\title{
FACTORS AFFECTING THE EFFICIENCY OF DELIVERING PROJECT CARGO FOR POWER PLANT PROJECTS IN NABIRE: A CASE STUDY AT PT. AGILITY INTERNATIONAL
}

\author{
Maya Tamara Trainor ${ }^{1}$, Nur Maulidah ${ }^{2}$, M. Rifni ${ }^{3}$ \\ 1. STMT Trisakti, 2. STMT Trisakti, 3. STMT Trisakti \\ corresponding author: Mayatrainor@gmail.com
}

\begin{abstract}
This research is focusing on a single project with intention of achieving in-depth understanding on how the handling of the power plant project deviation. This research is focus on the delivering process of heavy lift equipment to Nabire by PT. Agility International. How do PT. Agility International manage deviations happening in this project. The result shows that there is no delay regardless of the project problems and deviation, because of the present Temporary jetty.
\end{abstract}

Keywords: Project Cargo, Power Plant, Constructions, Deviations and Breakdown, Heavy Lift Equipment, Freight Forwarder

\section{Introduction}

A project is defined as a series of freight movements governed by specific contract in relation to starting and finishing dates, price, routing, service performance, operational, and reporting. The project will typically incorporate project cargo but it may also consist of regular Ocean Full Container Load usually refer to FCL or Less Container Load referred to LCL and air freight for project logistics client.

Logistics management is a process that consist of planning, implementing, controlling and reversing the service, storage of goods, and related information from origin to destination, it is one of many aspect of supply chain management (CSMP, 2016)

Project logistics can be defined as complex, special and unique activities. It can be described by technical and economic parameters determined of cost, time, and scope to support logistics management in operations. Provision project-specific features.

The project logistics may vary in scale and scope. It means that the logistics of a project can be implemented company-wide. Previous research explain that project is something that must be done in a limited time and 
budget but the result must be in high quality (Shan, Hu, Wang, \& Liu, 2014), A project covers all of those elements and distributes them across multiple independent items to increase complexity by magnitude sequence of each stage process. For example, the project may involve to build a warehouse to finish the products or choosing a new supplier of raw materials. In addition, in practice the researchers deal with the project logistics implementation of supply chain such as the procurement of project logistics. A supply chain project covers all of those elements and distributes them across multiple independent items to increase complexity by magnitude sequence of each stage process.

A project management main feature is an ability to get things done. The only one problem is there is no solution that leads to find uncertainty in the project. The uncertainty is controlled by planning at the various stages of the project, suggesting that there are acceptance, planning, executing and delivering phase. One variable that contributes was from the boundaries of the triangle of distance, time, and resource. If the reader assumes that there is limitation, therefore, one of the aspect from the triangle must be done. Project logistics is a complex field that covers great aspects. A project logistics manager has to ensure hundreds and thousands different available items, the supply, and well-being of the construction team (Steyn \& Lourens, 2017). The definition of a project indicates that it should make a transition and the action is a means of achieving it.

As a developing country, the development of power plants in Indonesia is a key factor in boosting an economy especially in remote area. A rising economy will be shown by the occurrence of high mobility, with adequate transportation (Muhammadiyah \& Majid, n.d.).

Nabire city is located at the last island of East Indonesia. The location of the site is in remote area with challenging condition of infrastructure and limited type of equipment. PT. Agility International has just completed 20 Mega Watts power plant in Nabire, Papua. It uses to mobilize all the equipment into Nabire with strict timeline in order to meet client's deadline and to ensure all equipment will be available on time in arrival by 
the mother vessel ex Finland.

There are countless factors affecting the efficiency of delivering project cargo in remote areas like Nabire. The purpose of this research is to be an integrated approach for power plant installation projects to resolve deviations and address deficiencies as exogenous variable and project cargo in Nabire as endogenous variable.

\section{Method}

Researcher determine the research to use qualitative methods, by utilizing SSM (soft system Methodology) approach as a framework. The SSM approach provide exploration, explanation, description, and emancipation of the phenomenon. From previous research, Soft System Methodology has been proven to be an effective method (Rafi \& Rifni, n.d.). The procedure for this research is explained below.

Procedure

The case study approach was adopted with observations and interviews. Examining the project as a process is done in order to create full understanding of the project itself. Other than observations, researcher conduct in depth interview, we collected the data of interview using email, in which Pt. Agility International provides full information such as project documentation and plans, and answers research questions based on the situation on the field. This data then interpreted by using researcher logical framework as tool of analysis.

If previous researcher discuss about understanding total quality management (Gimenez-Espin, Jiménez-Jiménez, \& Martínez-Costa, 2013) or service quality of project such as paper by Prakash et al. (Mohanty, 2015). Researcher notice that there are few to none research talking about the supply chain management for power plant projects. Because the lack of research is present for the topic, we intend to explore and look for answer of several Important question that are related to the project complex problem using SSM to develop clear answer for those critical question. The questions and problem we would like to solve is: 
1. How is the status of construction supply chain management for power plant project in Nabire?

2. What are the important phases of transporting heavy equipment for power plant construction project in remote area?

3. What are the major problems in transporting heavy equipment for power plant project in remote area?

4. What are the major issues in transporting heavy equipment for power plant project in remote area?

5. What are the characteristic of transporting heavy equipment to power plant projects in remote area?

6. How can project logistics in remote area be defined and improve the innovation of ever-changing flux in power plant construction?

\section{Discussion And Results}

This research discuss each critical questions we proposed, to develop answer that are comprehensive and clear based on the evidence derived from the interview result with the Agility manager.

1. How is the status of construction supply chain management for power plant project in Nabire?

In remote areas such as Nabire, infrastructures are limited. It caused of a degree of challenges for PT. Agility International in delivering heavy lift equipment in such area. The power plant project installations are considered a multi-year project. That explains why the power plant itself is still on progress of being installed.

2. What are the important phases of transporting heavy equipment for power plant construction project in remote area?

There are three important stages of transporting heavy lift equipment to Nabire, feasibility phase, planning phase, and execution phase. This answers are based on interviews

a) Feasibility Phase is when we do survey from port to jobsite to find deviations or obstacles while delivering heavy lift equipment to Nabire. 
b) The main objective of planning phase is to plan the routes along delivering the heavy lift equipment to jobsite according to their geographical condition.

c) Execution Phase deals with developing route plans, cost modeling, and project support tools essential for customers with complex movements requiring staging, sequencing, the precise coordination and also the delivery process of transporting heavy lift equipment to jobsite. There are three critical phases to deliver, there are:

1) Ship-to-Ship from mother vessel to LCT

2) Roll off from LCT to temporary jetty

3) Loading on foundation by jacking system

3. What are the major problems in transporting heavy equipment for power plant project in remote area?

The inadequate infrastructures always become the main problem of transporting heavy lift equipment to remote areas. Indonesia's logistics infrastructure mostly uses conventional system where the regulation is not enough to rule all of logistics-related activity, the regulations are mostly still sectoral and not comprehensive (S, n.d.). Predominantly in Nabire case, it takes $26.8 \mathrm{~km}$ from port to jobsite. Consequently, it will not be feasible to transport main engine with height of $4.4 \mathrm{~m}$ and weight 130 tons direct from the port. There are few obstacles along the journey such as bridge bracket and public community. Moreover, transportation will not be optimally due to longer travel time and the cargo operations can only be done during the day light. PT. Agility International team had to prepare alternative solution by utilizing temporary jetty with the approval from their client that may speed up the discharging process from the mother vessel to shorten the distance to the jobsite in order to eliminate the obstacles for journey from the port as well as avoiding public community area.

4. What are the major issues in transporting heavy equipment for power plant project in remote area?

The topic of power plant project in Nabire explains about the issues 
relevant to the process of its installation. One of the major issues is the characteristics of local resident. The local resident tends to demand to be involved during the project. Meanwhile, most of them do not qualify the standard. Increased workload could be caused by lack of qualified man power (Ricardianto, n.d.). It means the company needs to do recruitments, interviews and trainings until they are ready with the proper work within the project in Nabire. Not only time consuming, it would lead to inefficiency of cost. Another issue would be the local tradition that does not allow any working activities on Sundays because of spiritual reasons. This would decrease the productivity accordingly. Extreme weather could affect the process as well. Previous research found out that at this situations, project manager had to prepare for the worst case scenario in terms of calculating the risks (Ludvigsen \& Klæboe, 2014).

5. What are the characteristic of transporting heavy equipment to power plant projects in remote area?

a) Project management is unique. Every project has a very different task that leads to do different problems since there are no readymade solutions for every particular challenge. New solutions is needed to be implemented in every project since every project has very different case (Taylor, Sobotka, \& Czarnigowska, 2010).

b) Project has limited time with such high pressure and has high quality standards.

c) Installing power plant in such remote area leads higher pressure since there are limited sources and poor infrastructure.

6. How can project logistics in remote area be defined and improved innovatively in power plant installation?

The main idea to improve project logistics is by increase planning accuracy, decrease spillover, and decrease dependency of every aspect in a project. However, none of them is sufficient even in a highly controllable environment. The management of the project has many uncertainties. They become too complex to solve with traditional 
approaches. Soft Systems Methodology (SSM) is a system approach used to analyze and solve problems in such complex situations.

Stage 1: Enter the problematic situation

There must be an effective relationship between the client and the contractor for the development of long-term relationships and the integration of the installation process of the power plant, the type of completion to achieve the objective of the plant project of energy throughout the installation.

Stage 2: Express the problematic situation

When problems occurs, such as delays of product arrival, the client will most likely to be affected. For example, if a product would not arrive in time, their schedule of their power plant project will be messed up. This is due to the product necessary to the continuity of the power plant project. This lateness in schedule surely will cause the client's cost inefficiency.

Stage 3: Development of relevant root definitions

At a minimum, you must specify a root definition in SSM. The main objective of this step is to identify the key transformation. To ensure that the corresponding elements of the system are captured in a root definition, it should be possible to derive from the root definition using the CATWOE mnemonics (Checkland, 1989) as follows:

\section{Customer (C): Government}

2. Actor (A): company, supplier, investor, employee, manager, user

3. Transformation $(\mathrm{T})$ : greater capacity of electricity, better skills and knowledge

4. Weltanschauung (W): Satisfaction of the client in the execution of a project, so that both the client and the government are satisfied with the services because previous research found out that customers satisfaction is the main thing to be considered by the a freight forwarding company (Nurlita et al., 2016).

5. Owner (O): Government

6. Environment (E): high pressure, time and cost critical

Stage 4: creation of root definitions of conceptual models 
1. Feasibility phase: talks about the field studies and reviews of available infrastructure. The project staff needs to evaluate and asses the design data, the estimated cost and the planning of the purchases

2. Planning Phase: Establishment of basic geotechnical studies and electrical installations

3. Phase of execution

(a) Ship-to-ship from mother vessel to LCT

b) Roll off from LCT to temporary jetty

c) Loading on foundation by jacking system

Stage 5: comparing model with the real situations on the field

The model must be compared with real problems, for example, understanding each phase of the understanding the impact of each phase on the transport of heavy lift equipment to Nabire by FCL and / or LCL. Stage 6: define possible changes and how to handle the deviation The bracket bridge causes problem in the power plant project it causes the client to destroy the bridge and rebuild them. Also, it was $26.8 \mathrm{~km}$ far from port to jobsite.

We handle this situation by requesting our client to build temporary jetty which helps us to save more time and cost.

Stage 7: Actions to improve the problematic situation

The answers to dealing with such situations are planning, adding redundancy and reducing dependency between the components of the project. However, none of them is sufficient even in a highly controlled environment.

\section{Conclusion}

1. The power plant project in Nabire is still under construction until October 2018

2. There are three important phases of transporting heavy lift equipment for power plant project in Nabire, there are Feasibility Phase, Planning Phase, and Execution Phase

3. Three critical phases to deliver heavy lift : 

a) Ship to ship
b) Roll off from LCT to temporary jetty
c) Loading on foundation by jacking system

4. The major problem in transporting heavy lift equipment to remote area is the infrastructures

5. PT. Agility International team handles the deviations by utilizing temporary jetty to speed up the discharging process

6. A project management has number of uncertainty. Increase planning, add redundancy, and decrease the dependency between the components of the project is the way to manage the situation.

\section{References}

Aragonés-Beltrán, P., Chaparro-González, F., Pastor-Ferrando, J. P., \& PlaRubio, A. (2014). An AHP (Analytic Hierarchy Process)/ANP (Analytic Network Process)-based multi-criteria decision approach for the selection of solar-thermal power plant investment projects. Energy, 66, 222-238. https://doi.org/10.1016/j.energy.2013.12.016

Checkland, P.B. (1989) „Soft systems methodology“e, Human Systems Management, Vol. 8, No.4, pp.273-289.

CSCMP (Council for Supply Chain Management Professionals), 2016, CSCMP Supply chain management terms and glossary. Available from

http://cscmp.org/imis0/CSCMP/Educate/SCM_Definitions_and_Gloss ary_of_Terms/C

SCMP/Educate/SCM_Definitions_and_Glossary_of_Terms.aspx?hke $\mathrm{y}=60879588-\quad$ f65f-4ab5-8c4b-6878815ef921 Accessed on 21 November 2017.

Gimenez-Espin, J. A., Jiménez-Jiménez, D., \& Martínez-Costa, M. (2013). Organizational culture for total quality management. Total Quality Management \& Business Excellence, 24(5-6), 678-692. https://doi.org/10.1080/14783363.2012.707409

Shan, H., Hu, E., Wang, L., \& Liu, G. (2014). Study on antecedent variables of dual commitment in the transitional economy. Pakistan Journal of Statistics, 30(5), 939-955. https://doi.org/10.1007/978-3-662-43871-8

Steyn, J., \& Lourens, D. (2017). An Introduction to Project Logistics Management__, (May).

Taylor, P., Sobotka, A., \& Czarnigowska, A. (2010). Analysis of supply system models for planning construction project logistics, (October 2014), 37-41. https://doi.org/10.1080/13923730.2005.9636335

http://www.jocpr.com/articles/engineering-construction-project-sitelogistics-management.pdf Accessed on 15 November 2017 http://www.agility.com/EN/products-and-services/Pages/Project 
Logistics.aspx Accessed on 15 November 2017

Gimenez-Espin, J. A., Jiménez-Jiménez, D., \& Martínez-Costa, M. (2013). Organizational culture for total quality management. Total Quality Management \& Business Excellence, 24(5-6), 678-692. https://doi.org/10.1080/14783363.2012.707409

Ludvigsen, J., \& Klæboe, R. (2014). Extreme weather impacts on freight railways in Europe. Natural Hazards, 70(1), 767-787. https://doi.org/10.1007/s11069-013-0851-3

Mohanty, R. P. (2015). Understanding construction supply chain management for road projects Anand Prakash, 22(4), 414-435.

Muhammadiyah, U., \& Majid, S. A. (n.d.). Formulasi Kebijakan Sistem Policy Formulation of Sea, 3(2), 161-183.

Nurlita, L., Sekolah, S., Manajemen, T., Trisakti, T., Made, I., Sekolah, A., ... Trisakti, M. T. (2016). Loyalitas Pelanggan Pada Perusahaan Freight Forwarding Customer Loyalty of Freight Forwarding Company, 3(3), 299-308.

Rafi, S., \& Rifni, M. (n.d.). SOFT SYSTEMS METHODOLOGY PADA PENGEMBANGAN BANDAR UDARA PROVINSI SULAWESI BARAT SOFT SYSTEM METHODOLOGY-BASED ON DEVELOPMENT OF AIRPORT OF WEST SULAWESI, 4(2), 159176.

Ricardianto, P. (n.d.). Handling Standard Operating Procedure Export Document Ocean Freight, 2(1).

S, T. I. H. (n.d.). MULTIMODA DALAM MEWUJUDKAN VISI LOGISTIK INDONESIA 2025, 69-84. 